\title{
A three year follow-up of chemotherapy with oxamniquine in a Brazilian community with endemic schistosomiasis mansoni ${ }^{\star}$
}

\author{
A. C. Sleigh, ${ }^{1}$ K. E. Mott, ${ }^{1}$ J. T. França Silva, ${ }^{2}$ T. M. Muniz, ${ }^{2}$ E. A. Mota, ${ }^{3}$ M. L. Barreto, ${ }^{4}$ R. Hoff, ${ }^{1}$ \\ J. H. Maguire, ${ }^{1}$ J. S. Lehman ${ }^{+}$aNd I. SherLock ${ }^{2}$ \\ ${ }^{1}$ Dept. of Tropical Public Health, Harvard School of Public Health, Boston, MA, USA \\ ${ }^{2}$ Centro de Pesquisas Gonçalo Muniz da Fundação Oswaldo Cruz, Salvador, Bahia, Brazil \\ ${ }^{3}$ ICOMI Fellow, Federal University of Bahia, Brazil \\ ${ }^{4}$ Dept. de Medicina Preventiva, Federal University of Bahia, Brazil \\ +Deceased.
}

\begin{abstract}
Summary
Oral oxamniquine was tested as a control strategy for endernic schistosomiasis in a rural area of Bahia, Brazil. Adults were treated with a single dose $(12.5$ to $15 \mathrm{mg}$ per $\mathrm{kg}$ ) and children $(<12$ years old) with a total of $20 \mathrm{mg}$ per $\mathrm{kg}$ in two doses. The 191 (infected) persons treated represented $69 \%$ of the infected population in the study area. Follow-up stool examinations (Kato-Katz method) at one, 3, 6, 13, 25 and 33 months showed the cure rate declining from $80 \%$ at three months to $46 \%$ at 33 months. Over one half of those not cured showed a decrease in egg counts throughout the follow-up which, after 33 months, remained $66 \%$ below the pre-treatment levels. Stool examinations conducted on all study area residents during three years before chemotherapy showed the prevalence and intensity of Schistosoma mansoni infection to be high and stable. 33 months after the chemotherapy the prevalence was $41 \%$ and for infected individuals the geometric mean egg count was $121 \mathrm{epg}$, a decline of respectively $35 \%$ and $40 \%$ from pre-treatment levels for each index. Chemotherapy of infected persons with oxamniquine protected the community as a whole from high worm burdens for almost three years, although at this point the prevalence began to rise towards pretreatment levels.
\end{abstract}

\section{Introduction}

Oral oxamniquine has been shown in Brazil to be an efficacious treatment for Schistosoma mansoni infection (KArZ, 1977). To test chemotherapy with oxamniquine as a control strategy we treated infected residents of a community in Brazil where schistosomiasis is endemic and evaluated the change in prevalence and intensity of schistosomal infection in the community (the study population) and the cure rate and reduction in egg excretion in those treated (the treated population) over the following three years.

\footnotetext{
Materials and Methods

The Study Design

The study population included all residents (mostly subsistence farmers) living in a $25 \mathrm{~km}^{2}$ area within the Municipio of Castro Alves in the State of Bahia, Brazil. The characteristics of
}

endemic schistosomiasis in this population had been defined by earlier studies; faecal examinations had been done in January, 1974, by a gravity sedimentation method, and in April, 1974, by a modification of the Bell method (LeHMaN et al., 1976). Another stool survey was performed in January 1977 (gravity sedimentation method). Treatment was then offered to all individuals shown to be passing schistosome eggs on one or more of the three previous examinations. Stools were collected a fourth time immediately before treatment (April 1977) and processed by the modified Bell method. This was to permit evaluation of the stability of schistosomal infection in the population between April, 1974, and April 1977 in terms of prevalence and intensity as revealed by the two Bell examinations.

Most evaluations of the effectiveness of oxamniquine therapy done in Brazil since 1974 have used the Katz-modified Kato faecal examination method (KATZ et al., 1972). To facilitate comparison we therefore also processed the April, 1977 pretreatment specimens by the Kato-Katz method, and thereafter used this technique exclusively for faecal examinations performed on treated individuals at one, $3,6,13,25$, and 33 months posttreatment and at 13,25 , and 33 months on the untreated population. A commercially available kit was employed (Kit a.k. A. K. Indústria e Comércio Ltda., Belo Horizonte, Brazil) which has a plastic template that delivers a mean weight of $42 \mathrm{mg}$ of faeces. From 75 to $90^{\circ} \%$ of the study population were represented in the pre-and postchemotherapy stool surveys (see Table I).

$\star$ The Harvard component is directed by $\mathrm{Dr}$. Thomas $\mathrm{H}$. Weller and is supported by grants from the Edna McConnell Clark Foundation and the Wellcome Trust. Field and laboratory activities were performed in collaboration with Fundação Oswaldo Cruz, directed in Bahia by Dr. Italo Sherlock. Subsidiary grants were received from the Pan American Health Organization and Industria e Comércio S.A. (ICOMI).

Address reprint requests to Dr. T. H. Weller, Department of Tropical Public Health, Harvard School of Public Health, 665 Huntington Ave., Boston, MA 02115, USA. 
Table I-Proportion of the study population represented in the pre- and post-chemotherapy stool surveys ${ }^{+}$

\begin{tabular}{llccc}
\hline Survey (method) & Study area population & Number submitting stools & Response rate $\%$ \\
\hline April 1974 & (Bell) & 445 & 360 & 81 \\
\hline April 1977 & (Bell) & 425 & 96 \\
\hline April 1977 (Kato-Katz) & 442 & $330 \star \star$ & 75 \\
\hline May 1978 (Kato-Katz) & 442 & 340 & 81 \\
\hline May 1979 (Kato-Katz) & 420 & 336 & 81 \\
\hline January $1980 \quad$ (Kato-Katz) & 415 & 330 & 82
\end{tabular}

tResults of the January 1974 and 1977 qualitative surveys (sedimentation method) are not shown. Chemotherapy was administered immediately after the April 1977 survey.

*Based on the annual census preceding each stool survey.

$\star \star$ The Bell and Kato-Katz counts in April 1977 were performed on the same stools. However, as some Kato slides were damaged, not all stools were examined by both methods.

Table II-Comparison of the post-treatment subgroups to the treated population

\begin{tabular}{|c|c|c|c|c|c|c|c|}
\hline \multirow[b]{3}{*}{ Number of subjects } & \multirow{2}{*}{$\begin{array}{c}\text { Treated } \\
\text { population }\end{array}$} & \multicolumn{5}{|c|}{ Post-treatment follow-up subgroups } & \multirow[b]{2}{*}{$\begin{array}{c}33 \\
\text { months }\end{array}$} \\
\hline & & $\begin{array}{l}\text { one } \\
\text { month }\end{array}$ & $\stackrel{3}{\text { months }}$ & $\begin{array}{c}6 \\
\text { months }\end{array}$ & $\begin{array}{c}13 \\
\text { months }\end{array}$ & $\begin{array}{l}25 \\
\text { months }\end{array}$ & \\
\hline & 135 & 112 & 82 & 61 & 102 & 96 & 80 \\
\hline Mean age (years) ${ }^{\star}$ & 27 & 27 & 25 & 21 & 28 & 26 & 30 \\
\hline $\begin{array}{l}\text { Geometric mean egg }{ }^{\star} \\
\text { count (epg) pre-treatment }\end{array}$ & 224 & 248 & 225 & 184 & 245 & 241 & 220 \\
\hline $\begin{array}{l}\text { Proportion of pre-treatmen } \\
\text { egg counts }>100 \mathrm{epg}(\%)\end{array}$ & 73 & 75 & 70 & 64 & 73 & 72 & 69 \\
\hline $\begin{array}{l}\text { Proportion of children } \\
<12^{\star \star \star} \text { years old }(\%)\end{array}$ & 31 & 32 & 35 & 39 & 30 & 32 & 28 \\
\hline
\end{tabular}

$\star$ Based on the October 1977 census

$\star \star$ Based on April 1977 pre-treatment Kato-Katz counts

$\star \star \star$ Age based on Oct. 1976 census.

Table III-Cure rates observed after oxamniquine therapy

\begin{tabular}{lcccccc}
\hline & \multicolumn{5}{c}{ Months post-chemotherapy } \\
\cline { 2 - 6 } & 1 & 3 & 6 & 13 & 25 & 33 \\
\hline$\%$ children ${ }^{\star}$ cured $(N) \star \star$ & $56(36)$ & $69(29)$ & $50(24)$ & $60(30)$ & $39(31)$ & $36(22)$ \\
$\%$ adults cured $(N)$ & $86(76)$ & $87(53)$ & $89(37)$ & $71(72)$ & $75(65)$ & $50(58)$ \\
\hline$\%$ cured over-all $(\mathrm{N})$ & $76(112)$ & $80(82)$ & $74(61)$ & $68(102)$ & $64(96)$ & $46(80)$ \\
\hline
\end{tabular}

$\star<12$ years old at October 1976 census

$\star \star N=$ denominator for the percentage calculation 
Table IV-Egg count reduction in subjects not cured by oxamniquine

\begin{tabular}{|c|c|c|c|c|c|c|}
\hline & \multicolumn{6}{|c|}{ Months post-chemotherapy } \\
\hline & 1 & 3 & 6 & 13 & 25 & 33 \\
\hline $\begin{array}{l}\text { Number of subjects with egg counts } \\
\text { higher than or equal to pre-treatment level }\end{array}$ & 7 & 4 & 4 & 8 & 13 & 19 \\
\hline $\begin{array}{l}\text { Number of subjects with egg counts } \\
\text { lower than pre-treatment level }\end{array}$ & 20 & 12 & 12 & 25 & 22 & 24 \\
\hline $\begin{array}{l}\text { Arithmetic mean of the percentage } \\
\text { egg count reductions }( \pm 95 \% \text { confi- } \\
\text { dence interval)» }\end{array}$ & $74 \pm 10$ & $63 \pm 13$ & $76 \pm 13$ & $76 \pm 7$ & $71 \pm 10$ & $66 \pm 10$ \\
\hline
\end{tabular}

*Analysis included only the non-cured subjects with a post-treatment count lower than the pre-treatment count. $\%$ egg reduction $=$

$$
\frac{\text { (pre-treatment count-post-treatment count) }}{\text { pre-treatment count }} \times 100
$$

$95 \%$ confidence limits calculated from the formula $\bar{x} \pm\left(t_{n-1,0.05}\right)(s / \sqrt{n})$.

$\overline{\mathrm{x}}=$ mean; $\mathrm{s}=$ standard deviation; $\mathrm{t}_{\mathrm{n}-1,0.05}=$ one tail value for $\mathrm{t}$ at 0.05 probability level and $\mathrm{n}-1$ degrees of freedom

Table V-Comparison of prevalence and intensity* of Schistosoma mansoni infection in the total study population before and after selective chemotherapy with oxamniquine of a portion (191 persons) of the population

\begin{tabular}{lcccc}
\hline & April 1977 & May 1978 & May 1979 & January 1980 \\
\cline { 2 - 5 } Number of persons with stool examination & 330 & 340 & 336 & 330 \\
\hline $\begin{array}{l}\text { Prevalence of infection (percentage) } \\
\text { Geometric mean egg count of infected }\end{array}$ & 63 & 32 & 31 & 41 \\
\hline $\begin{array}{l}\text { individuals (epg) } \\
\text { Arithmetic mean egg count of infected } \\
\text { individuals (epg) } \pm \text { SEM }\end{array}$ & 201 & 88 & 114 & 121 \\
\hline
\end{tabular}

*All examinations performed by the Kato-Katz method

$\star \star$ Pre-treatment examination

\section{Administration of Oxamniquine}

After verbal explanation of the purpose and risks, 191 persons were treated in the presence of a physician (J.F.S.). Oxamniquine was provided (Pfizer Ouimica Ltda., São Paulo) as a syrup containing $50 \mathrm{mg}$ per $\mathrm{ml}$ (for children less than 12 years old) or as $250 \mathrm{mg}$ capsules. Each person was weighed. Children less than 12 years old received $20 \mathrm{mg}$ per $\mathrm{kg}$ divided into two equal doses six to eight hours apart and older individuals received 12.5 to $15 \mathrm{mg}$ per $\mathrm{kg}$ as a single oral dose. Pregnancy, jaundice, ascites, liver failure or any overt illness were contraindications to therapy although actually only the few women known or suspected to be pregnant were excluded. All persons were requested to remain at the treatment post for two hours and to report symptoms to the physicians who remained in the area for 48 hours.

\section{Result}

Only one person, a 21-year-old male, experienced a serious problem. He had returned home within half an hour of ingesting the oxamniquine and soon felt dizzy, collapsed and developed rapid movements of his arms and legs. The patient was observed by us and found to be drowsy and confused. He had an enlarged liver, no palpable splenomegaly, a pre-treatment Bell count of 255 eggs per $\mathrm{ml}$ of stool and no prior history of convulsions. Although he left the area shortly thereafter, his family reports that he has had no further problems.

\section{Effect of Oxamniquine Therapy}

a. Impact on the treated population: For analysis we defined the treated population as consisting of the 135 treated persons shown to be excreting eggs 
on the April 1977 pre-treatment Kato-Katz examination. Of this group of 135 persons, posttreatment stool examinations were performed on 112 at one month, 82 at three months, 61 at six months, 102 at 13 months, 96 at 25 months, and 80 at 33 months. Each of these follow-up subgroups was compared to the total treated population for inadvertent bias with reference to age and intensity of infection that might influence the results (KATZ, 1977; McMahoN, 1978) (Table II). Only the six months' group was not representative.

Cure rates ${ }^{\star}$ declined from a high of $80 \%$ at 3 months to $46 \%$ at 33 months (Table III). Adult cure rates were substantially higher than those for children, especially noteworthy after 25 months $(75 \%$ versus $39 \%)$. At the six follow-up examinations, between $24 \%$ and $46 \%$ of those not cured maintained egg counts at the original or higher levels. However in those non-cured individuals with a reduced egg output the decrease was significant and sustained (Table IV).

\section{Impact on the study population}

Comparison of the results of the two prechemotherapy Bell method stool surveys (April 1974 and 1977) showed that the prevalence rates changed only by $1 \%$ and that the geometric mean egg count for infected individuals changed by $12 \cdot 6 \%$. Thus schistosomal infection in the study population in the pre-treatment period was remarkably stable. The pre-treatment prevalence in the study area for the April 1977 Kato-Katz survey was $63 \%$. Therefore the 191 persons treated represented $69 \%$ of those infected in the study population. As a consequence of treatment the crude potential contamination factor (arithmetic mean egg count for infected persons multiplied by the prevalence) was decreased $83 \%$ at 13 months, $66 \%$ at 25 months and $59 \%$ at 33 months after the chemotherapy (Table V). However, we could not demonstrate a decline in the over-all or agestratified incidence rates, a variable probably influenced by the intermittent positivity of those with marginal egg count, as well as by the acquisition of new infections.

\section{Discussion}

Enthusiasm for oxamniquine in the treatment of $S$. mansoni infections stems from its effectiveness, its ease of administration, and its apparent innocuousness. However, there have now been 11 cases reported of transient behavioural disturbances following oxamniquine ingestion (KATZ et al., 1976; Coura, 1975; Campos et al., 1976) and BiNA et al. (1976) have reported a case of a 61-yearold alcoholic with a history of lapses of consciousness who suffered a generalized convulsion one hour after ingestion of the drug. We could not elicit a history of previous convulsions or psychic disturbances in the case of oxamniquine-associated epileptiform seizures that we report here. It would seem prudent to consider such a history a

${ }^{\star}$ Cure rates are defined as the percentage of subjects at any particular follow-up examination with stools negative for schistosome eggs. contraindication to oxamniquine therapy and to observe all patients for two hours after the drug is ingested.

The cure rates reported here resemble those obtained in earlier trials (KATZ, 1977; BINA, 1977). The drug was less efficacious in children than adults, as previously noted for oxamniquine and other schistosomicidal compounds (MCMAHON, 1978). However, schistosomal chemotherapy must be evaluated in broader terms for a reduction in the faecal egg count implies a concomitant decline in the worm burden and in the amount of environmental contamination, the dual goals of schistosomiasis control. Over one half of those not cured in this study maintained a decreased egg excretion throughout the 33 months of follow-up and these subjects, along with those who were cured, have benefited substantially from the chemotherapy. Treated persons not showing reduced egg counts may reflect the resistance of parasites to oxamniquine (GUIMARÃEs et al., 1979).

Despite a reduction of $83 \%$ in the crude potential contamination factor, one year after treatment we could not demonstrate a decline in transmission. The decreasing cure rate over time, especially notable in children, may reflect reinfection (KATz et al., 1978). However, we have shown that mass chemotherapy with oxamniquine, even with a coverage of only $69 \%$ of the infected individuals, can give the community as a whole a respite from high schistosomal burdens for at least three years, at which point mean egg counts were still almost $50 \%$ below pre-treatment levels. However at the three-year mark cure rates had fallen sharply and the community prevalence of infection was beginning to rise, implying that the protection afforded by the chemotherapy was waning. Probably the appropriate role for community based chemotherapy is to free the population from heavy infections while a definitive solution is developed, i.e,, education of the population, improved sanitation, and the development of safe and convenient water supplies.

\section{Acknowledgements}

The study is a collaborative project involving the Centro de Pesquisas Gonçalo Muniz da Fundaçaõ Oswaldo Cruz, the Harvard School of Public Health and the Federal University of Bahia (UFBa). In Brazil, laboratory facilities have been provided by the Faculdade de Medicina through the Dean, Dr. Renato Tourinho Dantas, and UFBa Rector, Professor Augusto Mascarenhas. Logistic support was provided by the Pan American Health Organization through Drs. Mauricio Martins da Silva and Adolfo Perez-Miravete in Washington, D.C. and Drs. Frederico Bresani Silva and Carlos D'Avila in Brazilia. In Castro Alves Drs. Reinaldo Rosa and Clywton Sother furnished vital local assistance. The field study was assisted by Snra Alice Ferreira and Snrs Tomé Silva de Oliveira, Tomas Campos and José Pedrosa. The laboratory work and data tabulation were assisted by Snars Tereza Maisk de Paiva, Vera Menezes, Valdice Soledade and Snr Roberto Magalhães. At Harvard Dr. Thomas Weller and Dr. Markley Boyer have provided 
administrative support and scientific advice for the study and have given helpful criticism in the preparation of this manuscript.

\section{References}

Bina, J. C. \& Spinola, A. (1976). Convulsão associado ao uso de oxamniquine. Relato de um caso. Revista da Sociedade Brasileira de Medicina Tropicale, 10, 221-223.

Bina, J. C. (1977). Drogas esquistossomicidas. Revista Médica de Bahia, 23, 208-221.

Campos, R., Cimerman, B., Silva, N. P., Soloman, N. L. \& Sapienza, P. (1976). Tratamento da esquistossomose mansonica pelo oxamniquine em região não endemica. Resumos do XII Congr. Soc. Bras. Med. Trop. Belem-Pará. 15-19 fevereiro de 1976.

Coura, J. R. (1975). International Conference on Schistosomiasis. Cairo, October 18-25, 1975. (Ministry of Health of Egypt).

Guimarães, R. X., Tchakerian, A., Dias, L. C., de Almeida, F. M., Vilela, M. P., Cabeca, M. \& Takeda, A. K. (1979). Resistencia ao hycanthone e oxmniquine em doentes com esquistossomose forma clinica hepato-intestinal. Revista da Associaf̧ao Medica Brasileira 25, 48-49.

Katz, N., Chaves, A., \& Pellegrino, J. (1972). A simple device for quantitative determination of Schistosoma mansoni eggs in faeces examined by the thick smear technique. Revista do Instituto de Medicina Tropical de São Paulo, 14, 397-400.

Katz, N., Grinbaum, E., Chaves, A., Zicker, F., \& Pellegrino, J. (1976). Clinical trials with oxamniquine by oral route in Schistosomiasis mansoni. Revista do Instituto de Medicina Tropical do São Paulo, 18, 371-377.

Katz, N. (1977). Chemotherapy of Schistosomiasis mansoni. In: Advances in Pharmacology and Chemotherapy, 14, 1-70. New York: Academic Press.

Katz, N., Zicker, F., Rocha, R. S., \& Oliveira, V. R. (1978). Reinfection of patients in schistosomiasis mansoni endemic areas. I. Influence of age and worm burden. Revista do Instituto de Medicina Tropical de São Paulo, 20, 273-278.

Lehman, J. S., Mott, K. E., Morrow, R. H., Muniz, T. M., \& Boyer, M. H. (1976). The intensity and effects of infection with Schistosoma mansoni in a rural community in northeast Brazil. American Fournal of Tropical Medicine and Hygiene, 25, 285-294.

McMahon, J. E., (1978). Treatment of schistosomiasis. Factors affecting chemotherapy and reflections on ideal drug treatment. Tropical and Geographical Medicine, 30, 161-174.

Accepted for publication 26th February, 1980.

\section{To Local Secretaries}

News items of topical interest will, from the current volume of the Transactions, be included as soon as possible after they have been received, rather than delayed until the last issue of the volume and summarized. Items for publication should be sent to The Editor, Transactions, Winches Farm Field Station, 395 Hatfield Road, St. Albans, Herts AL4 OXQ, England. Correspondence on other matters (new Fellows, subscriptions etc.) should continue to be sent to Manson House. 